\title{
SYNTHESIS CHARACTERIZATION AND ANTIBACTERIAL ACTIVITY OF IRON OXIDE NANOPARTICLES AGAINST STAPHYLOCOCCUS EPIDERMIDIS
}

\author{
POONAM SANGWAN ${ }^{1 *}$, HARISH KUMAR ${ }^{2}$ \\ ${ }^{1}$ Department of Chemistry, GC Hisar, Haryana, India. ${ }^{2}$ Department of Chemistry, Central University of Mahendergarh, Haryana, India. \\ Email: poonam.sangwan35@gmail.com
}

Received: 25 January 2020, Revised and Accepted: 11 August 2020

\section{ABSTRACT}

Objective: This study deals with the synthesis of iron oxide nanoparticles by sol-gel technique, their characterization and antibacterial activity of these nanoparticles against Staphylococcus epidermidis.

Methods: Hematite $\left(\alpha-\mathrm{Fe}_{2} \mathrm{O}_{3}\right)$ nanoparticles were successfully synthesized by sol-gel method using tetraethyl orthosilicate as a precursor. The structural morphology, size, and chemical state of synthesized iron oxide nanoparticles have been investigated by X-ray diffractometer (XRD), transmission electron microscopy, Fourier transform infrared spectroscopy, and ultraviolet-visible spectroscopy. The antibacterial activities of these iron oxide nanoparticles were investigated on a pathogenic bacteria S. epidermidis, by measuring the zone of inhibition and colony-forming units on solid medium and by measuring the optical density of the culture solution. Antibacterial activity of iron oxide nanoparticles was also compared with well-known standard antibiotics.

Results: It was confirmed from XRD data that the synthesized iron oxide nanoparticles were hematite $\left(\alpha-\mathrm{Fe}_{2} \mathrm{O}_{3}\right)$ nanoparticles. Average particle size of the $\mathrm{Fe}_{2} \mathrm{O}_{3}$ nanoparticles was found to be $38.57 \mathrm{~nm}$ by XRD characterization. The antibacterial activity of Fe $\mathrm{O}_{3}$ nanoparticles was almost comparable to the most of the standard antibiotics (taken for comparison), but $\mathrm{Fe}_{2} \mathrm{O}_{3}$ nanoparticles were found to be more effective than antibiotic ampicillin and sulfatriad toward S. epidermidis.

Conclusion: This study shows that $\mathrm{Fe}_{2} \mathrm{O}_{3}$ nanoparticles possess good antibacterial properties; therefore, these metal nanoparticles may be used in place of antibiotics. These inorganic metal nanoparticles can be used by pharmaceutical industries for further research regarding the toxicity study for its use in human being.

Keywords: $\mathrm{Fe}_{2} \mathrm{O}_{3}$ Sol-Gel, X-ray diffractometer, Transmission electron microscopy.

(c) 2020 The Authors. Published by Innovare Academic Sciences Pvt Ltd. This is an open access article under the CC BY license (http://creativecommons. org/licenses/by/4. 0/) DOI: http://dx.doi.org/10.22159/ajpcr.2020.v13i9.36938

\section{INTRODUCTION}

Nanosize metallic nanoparticles have been the subject to research in recent years because these materials represent an intermediate dimension between bulk materials and atoms/molecules. In recent years, the field of nanoscience and nanotechnology has resulted in the production of different kinds of metal and metal oxide nanoparticles with antibacterial effects due to their high stability and non-toxic nature [1]. Among these metal nanoparticles, iron oxide nanoparticles have received special consideration because of their numerous scientific and technological applications such as biosensor [2,3], antimicrobial activity [4], ferrofluids, magnetic storage media, magnetic refrigeration, magnetic resonance imaging [5], cancer treatments [6,7], cell sorting, and targeted drug delivery. Iron oxide nanoparticles have also been widely used in biomedical research because of their biocompatibility and magnetic properties [8,9]. The synthesis of these IO nanoparticles is carried out by different chemical approaches such as sol-gel $[10,11]$, hydrothermal [12], co-precipitation [13] surfactant mediated/template synthesis, microemulsion [14], electrochemical, and laser pyrolysis. The development of new resistant strains of bacteria to current antibiotics has become a serious problem in public health; therefore, there is a strong incentive to develop new bactericides from various sources. Recent advancement in the field of nanotechnology has provided an attractive method for synthesizing alternative antimicrobial agents and reducing biofilm formation. Although nanoparticles have long been known to exhibit a strong toxicity to a wide range of microorganisms $[15,16]$, very little is known about the toxicity of iron oxide nanoparticles toward these microorganisms. In the present study, an attempt has been made to synthesize iron-oxide nanoparticles by sol-gel technique and these particles were characterized by various techniques along with the evaluation of their antibacterial activity against human pathogenic Gram-positive bacteria with a view to explore their pharmaceutical applications.

\section{MATERIALS AND METHODS}

\section{Materials}

All of the chemicals used in the experiment were of analytical grade and obtained from standard chemical sources. The Staphylococcus epidermidis (microbial type culture collection [MTCC] NO. 3382) was obtained from MTCC, Institute of Microbial Technology, Chandigarh.

\section{Synthesis of $\mathrm{Fe}_{2} \mathrm{O}_{3}$ nanoparticles}

$\mathrm{Fe}_{2} \mathrm{O}_{3}$ nanoparticles were synthesized using sol-gel method. The procedure uses $\mathrm{FeSO}_{4} .7 \mathrm{H}_{2} \mathrm{O}$ solution of pH 1-2, ethanol, and tetraethyl orthosilicate (TEOS) as the precursor material. The $\mathrm{Fe}_{2} \mathrm{O}_{3}$ nanoparticles were prepared by mixing $\mathrm{FeSO}_{4} \cdot 7 \mathrm{H}_{2} \mathrm{O}$ solution drop by drop into the flask containing 1:4 TEOS and ethanol solution with continuous stirring. The resulting solution was heated at $70.0^{\circ} \mathrm{C}$ with continuous stirring in a closed container for $6.0 \mathrm{~h}$. The resulting solution was then kept in the oven at $100.0^{\circ} \mathrm{C}$ for $10-15$ days and after that, the particles were kept in muffle furnace at $400.0^{\circ} \mathrm{C}$ for $4.0 \mathrm{~h}$. Reddish-brown $\mathrm{Fe}_{2} \mathrm{O}_{3}$ nanoparticles were obtained.

\section{Characterization techniques}

The size, structure, morphology, and magnetic properties of as prepared metal nanoparticles were characterized by Fourier transform infrared (FT-IR) (Shimadzu corp-02014) in the wavelength range 
400-4000/cm, ultraviolet (UV)-visible spectroscopy (Shimadzu 1800 ) in the wavelength range $200-1000 / \mathrm{cm}, \mathrm{X}$-ray diffractometer (XRD) (Rigaku mini-2 using Cu $\alpha 1, \lambda=0.15406 \mathrm{~nm}$ radiations), and transmission electron microscopy (TEM) (FEI-Philips, Morgagni 286D with magnification up to 2,80,000x, Acc. Voltage: $100 \mathrm{Kv}$ ).

\section{Antibacterial study}

Antibacterial activity of the $\mathrm{Fe}_{2} \mathrm{O}_{3}$ nanoparticles against a Gram-positive S. epidermidis was investigated by measuring zone of inhibition (ZOI), colony-forming unit (CFU), and optical density (OD). The antibacterial activity of these $\mathrm{Fe}_{2} \mathrm{O}_{3}$ nanoparticles was also compared with wellknown antibiotics. The bacterial test organisms $S$. epidermidis was

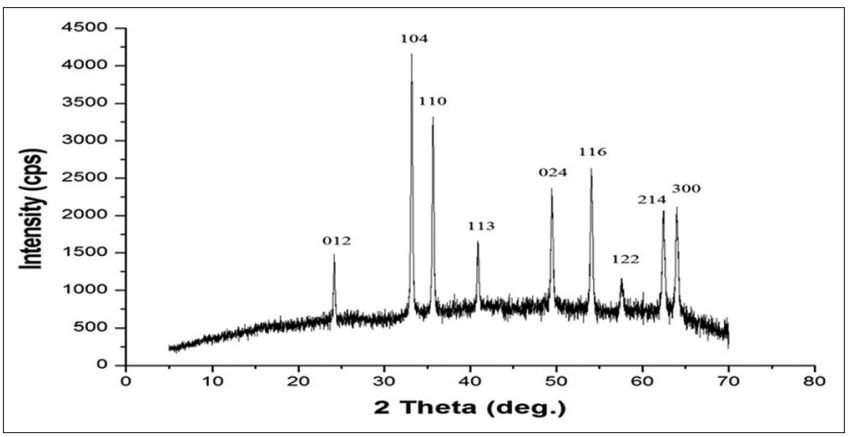

Fig. 1: X-ray diffractometer pattern of iron oxide nanoparticles synthesized by sol-gel technique

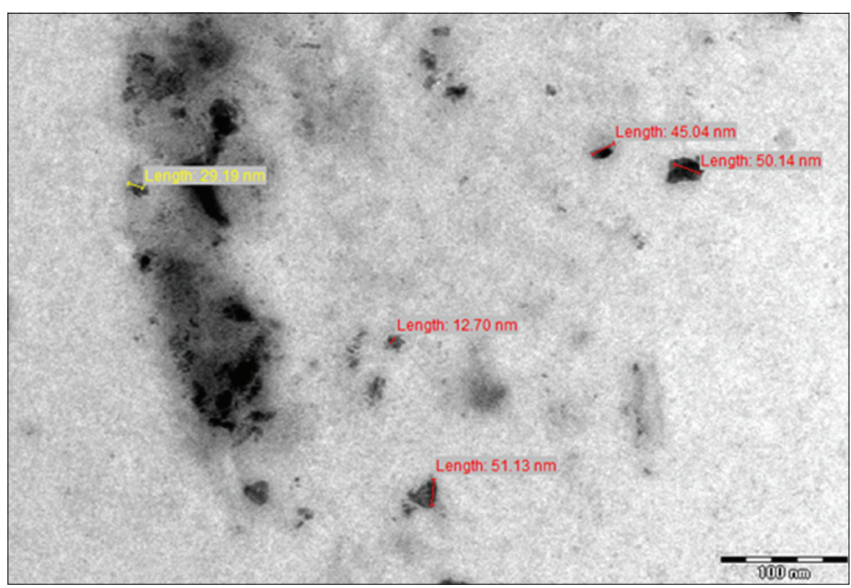

Fig. 2: Transmission electron microscopy image of iron oxide nanoparticles synthesized by sol-gel technique grown in nutrient broth at $37^{\circ} \mathrm{C}$ for $24 \mathrm{~h}$. The ZOI was measured by agar well diffusion method. A100 $\mu \mathrm{l}$ of the bacterial culture was spread onto the solidified agar plates. The wells were prepared in the agar medium with the help of a cork borer. These wells were subsequently loaded with different concentrations of $\mathrm{Fe}_{2} \mathrm{O}_{3}$ nanoparticles suspension in doubledistilled water. The $\mathrm{CFU}$ of the bacterial culture was evaluated with different concentrations $(10,15$, and $20 \mathrm{mg} / \mathrm{ml})$ of $\mathrm{Fe}_{2} \mathrm{O}_{3}$ nanoparticles using the standard broth dilution method. The growth behavior of the $S$. epidermidis was investigated by measuring the OD through the administration of different concentrations of $\mathrm{Fe}_{2} \mathrm{O}_{3}$ nanoparticles into the dilute solution of the broth.

\section{RESULTS AND DISCUSSION}

\section{Characterization of iron oxide nanoparticles}

Fig. 1 shows the X-ray diffraction pattern of the iron oxide nanoparticles synthesized by sol-gel method. The X-ray diffraction pattern revealed major peaks at $2 \theta$ values of 24.13 (012), 33.17 (104), 35.65 (110), 40.86 (113), 49.46 (024), 54.04(116), 57.6 (122), 62.49 (214), and $63.98(300)$, respectively $[17,18]$. These XRD peaks correspond to pure $\alpha-\mathrm{Fe}_{2} \mathrm{O}_{3}$ (hematite) nanoparticles. The XRD patterns were indexed to pure hexagonal structure with lattice parameter of $a=5.038 \AA$ and $c=13.772 \AA$. The diffraction peaks correspond with JCPDS card no. 01-1030 and 87-1164, indicating that the $\alpha-\mathrm{Fe}_{2} \mathrm{O}_{3}$ nanoparticles are crystalline structure. Average particle size of the $\mathrm{Fe}_{2} \mathrm{O}_{3}$ nanoparticles was found to be $38.57 \mathrm{~nm}$ using Scherrer's formula $\mathrm{d}=\mathrm{K} \lambda / \beta \cos \theta$.

Fig. 2 shows the TEM images of synthesized iron oxide nanoparticles. The particles appeared to be almost rod shaped. It can be seen from Fig. 2 that there is a uniform distribution of particle with mean particle size $37.64 \mathrm{~nm}$ which is nearly in close agreement with the XRD result.

Fig. 3 shows the FT-IR spectra of iron oxide nanoparticles synthesized by sol-gel method. The characteristic absorption bands at 557, 520, 482, and $434 \mathrm{~cm}^{-1}$ corresponds to the $\mathrm{Fe}-\mathrm{O}$ stretching and bending vibration mode of $\alpha-\mathrm{Fe}_{2} \mathrm{O}_{3}$ nanoparticles $[19,20]$. The peak centered at $3425 \mathrm{~cm}^{-1}$ corresponds to the stretching vibration of intermolecular hydrogen bond $(\mathrm{O}-\mathrm{H})$ existing between the adsorbed water molecules and indicates some amount of hydroxyl group.

Fig. 4 shows the UV-visible spectra of iron oxide nanoparticles synthesized by sol-gel method. An absorption band at $296 \mathrm{~nm}$ is characteristic of iron nanoparticles.

\section{Antibacterial activity of iron oxide nanoparticles}

Fig. 5a shows the ZOI produced by different concentrations $(25,26,27$, 28 , and $29 \mathrm{mg} / \mathrm{ml}$ ) of the $\mathrm{Fe}_{2} \mathrm{O}_{3}$ nanoparticles against S. epidermidis. It was observed that the ZOI increases with an increase in the concentration of the $\mathrm{Fe}_{2} \mathrm{O}_{3}$ nanoparticles. Fig. $5 \mathrm{~b}$ and $\mathrm{c}$ shows the antibacterial activity

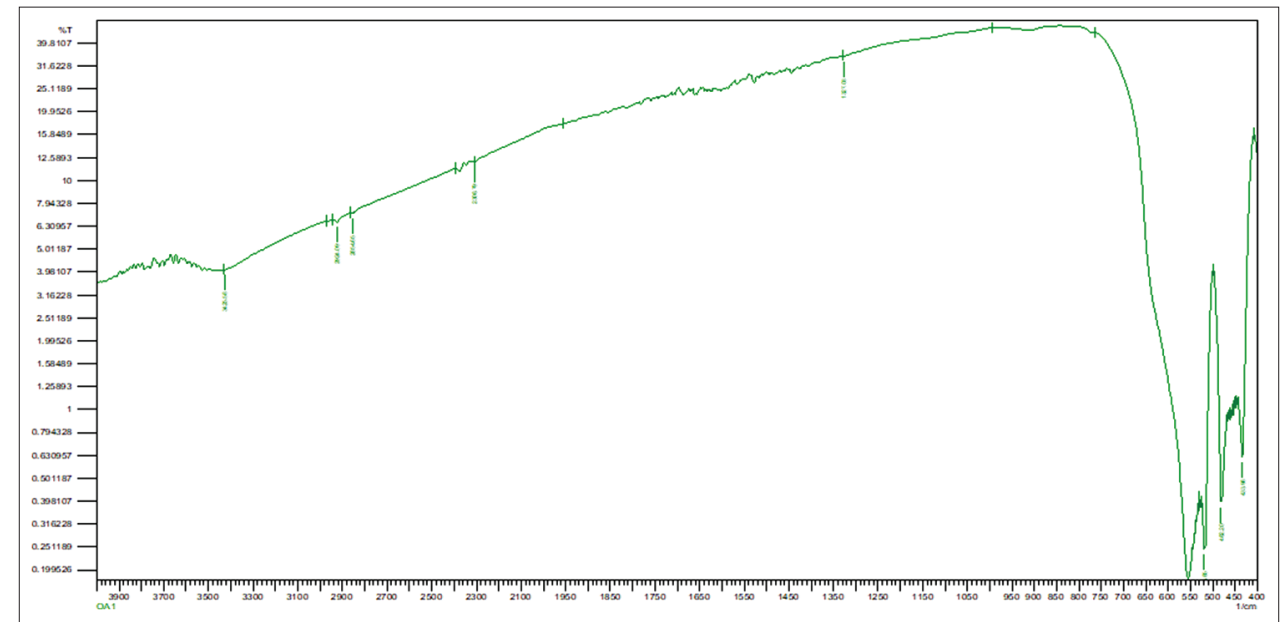

Fig. 3: Fourier transform infrared spectra of iron oxide nanoparticles synthesized by sol-gel technique 


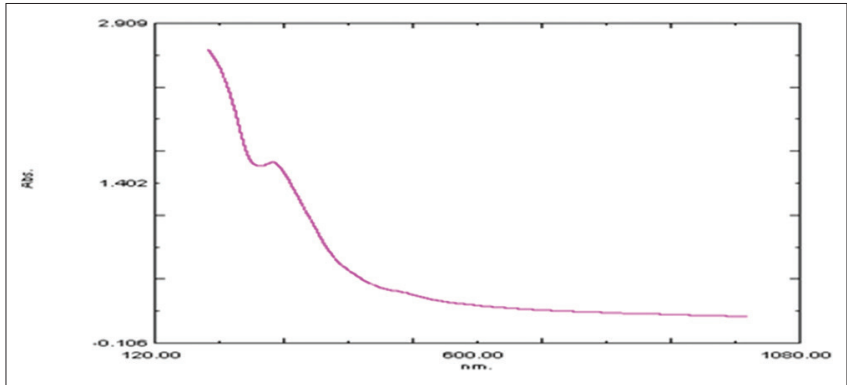

Fig. 4: Ultraviolet-visible absorption spectra of iron oxide nanoparticles synthesized by sol-gel technique

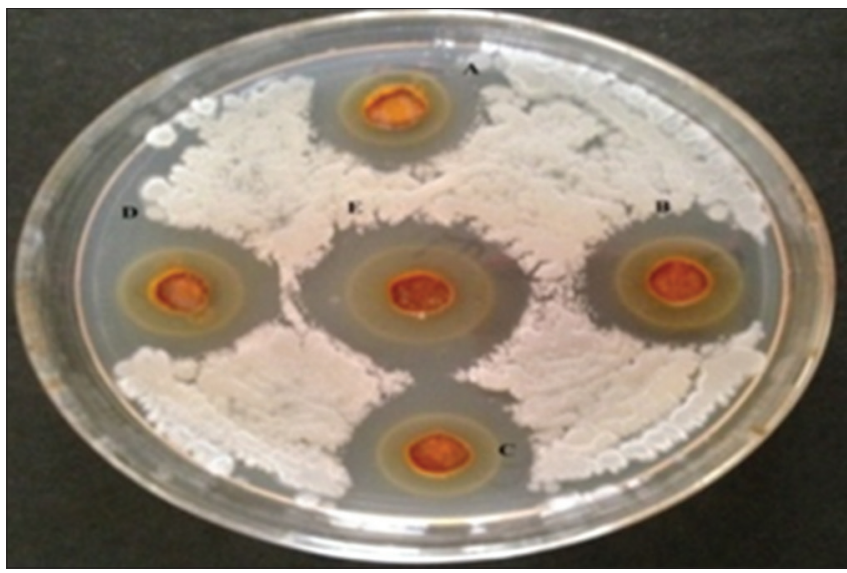

Fig. 5a: Antibacterial activity of iron oxide nanoparticles at different concentration against Staphylococcus epidermidis $(\mathrm{A}=\mathbf{2 5}$ $\mathrm{mg} / \mathrm{ml}, \mathrm{B}=26 \mathrm{mg} / \mathrm{ml}, \mathrm{C}=27 \mathrm{mg} / \mathrm{ml}, \mathrm{D}=28 \mathrm{mg} / \mathrm{ml}, \mathrm{E}=29 \mathrm{mg} / \mathrm{ml}$ )

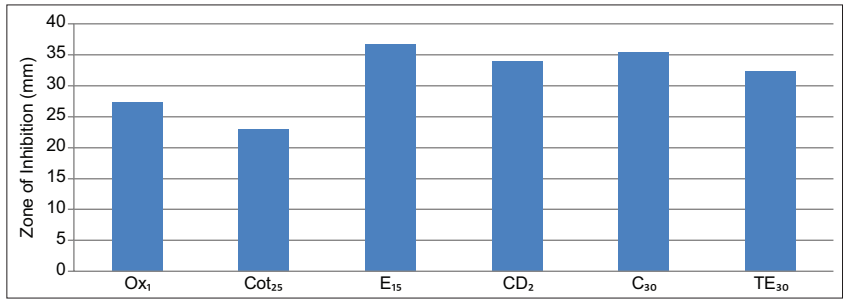

Fig. 5b: Zone of inhibition produced by oxacillin $\left(\mathrm{ox}_{1}\right)$, cotrimoxazole $\left(\operatorname{Cot}_{25}\right)$, erythromycin $\left(E_{15}\right)$, clindamycin $\left(\mathrm{CD}_{2}\right)$, chloramphenicol $\left(\mathrm{C}_{30}\right)$, and tetracycline $\left(\mathrm{TE}_{30}\right)$

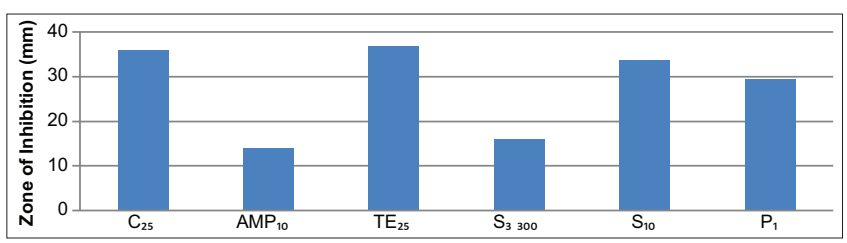

Fig. 5c: Zone of inhibition produced by chloramphenicol $\left(C_{25}\right)$, ampicillin ( $\left.A M P_{10}\right)$, tetracycline $\left(\mathrm{TE}_{25}\right)$, sulfatriad $\left(\mathrm{S}_{3300}\right)$, streptomycine $\left(\mathrm{S}_{10}\right)$, and Penicillin $\left(\mathrm{P}_{1}\right)$

of standard antibiotics against $S$. epidermidis. The antibiotics were taken in the form of hexa discs. Hexa Disc HX-022 consists of sulfatriad (300 mcg), tetracycline ( $25 \mathrm{mcg}$ ), ampicillin (10 mcg), chloramphenicol (25 mcg), penicillin G (1 unit), streptomycin (10 mcg) and hexa disc HX-034 consists of co-trimoxazole $(25 \mathrm{mcg})$, clindamycin $(2 \mathrm{mcg})$, oxacillin (1 mcg), erythromycin (15 mcg), tetracycline $(30 \mathrm{mcg})$, and chloramphenicol $(30 \mathrm{mcg})$. It was found that all of these antibiotics

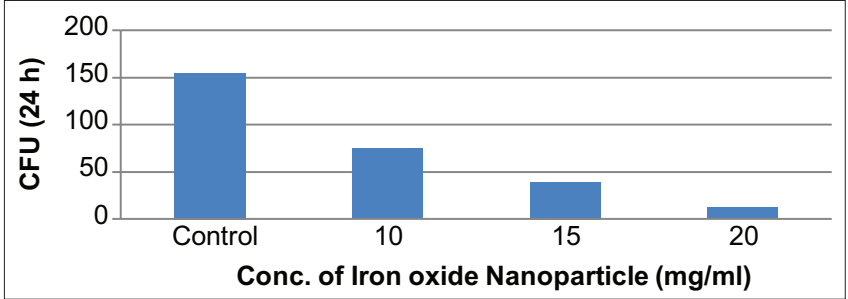

Fig. 5d: Colony-forming unit characterization of iron oxide nanoparticles against Staphylococcus epidermidis

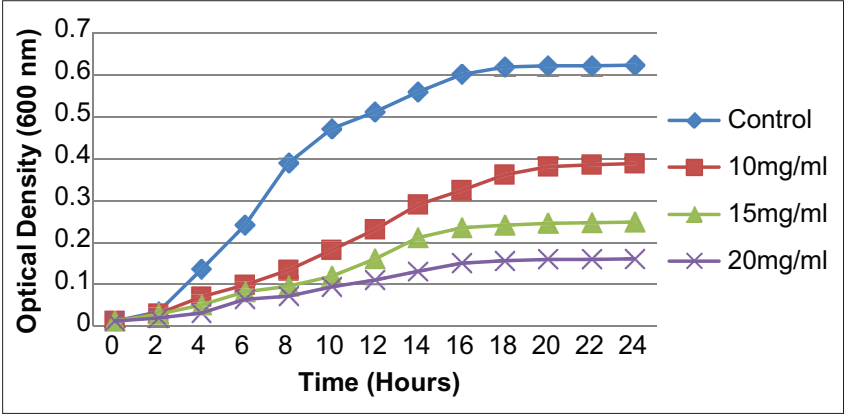

Fig. 5e: Effect of iron oxide nps on the growth of Staphylococcus epidermidis in terms of optical density

were effective against $S$. epidermidis. $\mathrm{The}_{2} \mathrm{O}_{3}$ nanoparticles were also showed good antibacterial activity against $S$. epidermidis. Fig. $5 \mathrm{~d}$ shows the $\mathrm{CFU} / \mathrm{ml}$ of the dilute bacterial broth supplemented with different concentrations $(0,10,15$, and $20 \mathrm{mg} / \mathrm{ml})$ of $\mathrm{Fe}_{2} \mathrm{O}_{3}$ nanoparticles. It was found that the CFU has been reduced significantly with an increase in the conc. of the $\mathrm{Fe}_{2} \mathrm{O}_{3}$ nanoparticles. Fig. $5 \mathrm{e}$ shows the time-dependent changes in the bacterial growth monitored at a regular interval of $2 \mathrm{~h}$ (up to $24 \mathrm{~h}$ ) by measuring OD of the control and bacterial solutions supplemented with different concentrations $(10,15$, and $20 \mathrm{mg} / \mathrm{ml})$ of $\mathrm{Fe}_{2} \mathrm{O}_{3}$ nanoparticles. It is clear that slope of the bacterial growth curve is continuously decreased with increasing concentration of the nanoparticles.

\section{CONCLUSION}

In this study, iron oxide nanoparticles of mean size $38.57 \mathrm{~nm}$ were synthesized using easy and economical sol-gel technique. Antibacterial activity of these $\mathrm{Fe}_{2} \mathrm{O}_{3}$ nanoparticles against a Gram-positive bacterium, $S$. epidermidis was investigated by measuring $\mathrm{ZOI}, \mathrm{CFU}$, and $\mathrm{OD}$. Antibacterial activity of these $\mathrm{Fe}_{2} \mathrm{O}_{3}$ nanoparticles was also compared with standard antibiotics. The minimum inhibitory concentration of these nanoparticles was found to be $22 \mathrm{mg} / \mathrm{ml}$ for the investigated bacteria. The CFUs decrease with an increase in the conc. of the iron oxide nanoparticles. The results obtained from the ZOI, CFU, and OD measurements were in close conformity with each other. It was found that antibacterial activity of $\mathrm{Fe}_{2} \mathrm{O}_{3}$ nanoparticles was almost comparable to the most of the standard antibiotics (taken for comparison), but $\mathrm{Fe}_{2} \mathrm{O}_{3}$ nanoparticles were found to be more effective than antibiotics ampicillin and sulfatriad toward S. epidermidis. This study shows that $\mathrm{Fe}_{2} \mathrm{O}_{3}$ nanoparticles possess good antibacterial properties. In recent times due to excessive use of antibiotics, the pathogens become resistant to most of the antibiotics and the excess use of these antibiotics adversely affects our immune system. Consequently, the metal nanoparticles can be used in pharmaceutical industries and provides a path for further research regarding the toxicity study for its use in human being.

\section{ACKNOWLEDGMENT/FUNDING}

The authors gratefully acknowledge the support of the University Grant Commission of India for this research work. 


\section{AUTHOR'S CONTRIBUTIONS}

Poonam Sangwan was involved the synthesis, characterization, and antibacterial study of iron oxide nanoparticles.

Harish Kumar guided this research at each and every step.

\section{CONFLICTS OF INTEREST}

The authors declare that they have no conflicts of interest.

\section{REFERENCES}

1. Lee C, Kim JY, Lee WI, Nelson KL, Yoon J, Sedlak DL. Bactericidal effect of zero-valent iron nanoparticles on Escherichia coli. Environ Sci Technol 2008;42:4927-33.

2. Hasanzadeh M, Shadjou N, Guardia ML. Iron and iron-oxide magnetic nanoparticles as signal-amplification elements in electrochemical biosensing. Trends Analyt Chem 2015;72:1-9.

3. George JM, Antony A, Mathew B. Metal oxide nanoparticles in electrochemical sensing and biosensing. Mikrochim Acta 2018;185:358.

4. Behera SS, Patra JK, Pramanik K, Panda N, Thatoi H. Characterization and evaluation of antibacterial activities of chemically synthesized iron oxide nanoparticles. World J Nano Sci Eng 2012;2:196-200.

5. Beets-Tan RG, Van Engelshoven JM, Greve JW. Hepatic adenoma and focal nodular hyperplasia: MR findings with superparamagnetic iron oxide-enhanced MRI. Clin Imaging 1998;22:211-5.

6. Martinkova P, Brtnicky M, Kynicky J, Pohanka M. Iron oxide nanoparticles: Innovative tool in cancer diagnosis and therapy. Adv Healthc Mater 2017;7:1-14.

7. Saeed M, Ren W, Wu A. Therapeutic applications of iron oxide based nanoparticles in cancer: Basic concepts and recent advances. Biomater Sci 2018;6:708-25.

8. Gupta AK, Gupta M. Synthesis and surface engineering of iron oxide nanoparticles for biomedical applications. Biomaterials 2005;26:3995-4021.

9. Lida H, Takayanagi K, Nakanishi T, Osaka T. Synthesis of $\mathrm{Fe}_{3} \mathrm{O}_{4}$ nanoparticles with various sizes and magnetic properties by controlled hydrolysis. J Colloid Interface Sci 2007;314:274-80.

10. Lewandowska J, Staszewska M, Kepczynski M, Szuwarzynski M, Latkiewicz A, Olejniczak Z, et al. Sol-gel synthesis of iron oxide-silica composite microstructures. J Solgel Sci Technol 2012;64:67-77.

11. Reda SM. Synthesis of $\mathrm{ZnO}$ and $\mathrm{Fe}_{2} \mathrm{O}_{3}$ nanoparticles by sol-gel method and their application in dye-sensitized solar cell. Mater Sci Semicond Process 2010;13:417-25.

12. Ma J, Lian J, Duan X, Liu X, Zheng W. $\alpha-\mathrm{Fe}_{2} \mathrm{o}_{3}$ : Hydrothermal synthesis, magnetic and electrochemical properties. J Phys Chem C 2010;114:10671-6.

13. Al-Alawy AF, Al-Abodi E, Kadhim RM. Synthesis and characterization of magnetic iron oxide nanoparticles by co-precipitation method at different conditions. Univ Baghdad Eng J 2018;24:60-72.

14. Kanda WK, Horwongsakul S. The preparation of iron (III) oxide nanoparticles using W/O microemulsion. Mater Lett 2011;65:2820-2.

15. Sangwan P, Kumar H, Rani R. Wet chemical synthesis, characterization, and antibacterial activity of molybdenum oxide nanoparticles against Staphylococcus epidermidis and Enterobacter aerogenes. Asian J Pharm Clin Res 2019;12:59-63.

16. Sangwan P, Kumar H. Synthesis, characterization and antibacterial activities of chromium oxide nanoparticles against Klebsiella pneumoniae. Asian J Pharm Clin Res 2017;10:1-4.

17. Mohammadi SZ, Motlagh MK, Jahani S, Yousef M. Synthesis and characterization of $\alpha-\mathrm{Fe}_{2} \mathrm{O}_{3}$ nanoparticles by microwave method. Int $\mathrm{J}$ Nanosci Nanotechnol 2012;8:87-92.

18. Bagheri S, Chandrappa KG, Hamid SB. Generation of hematite nanoparticles via sol-gel method. Res J Chem Sci 2013;3:62-8.

19. Zhao B, Wang Y, Guo H, Wang J, He Y, Jiao Z, et al. Iron oxide (III) nanoparticles fabricated by electron beam irradiation method. Mater Sci Pol 2007;25:1143-8.

20. Sahoo SK, Agarwal K, Singh AK, Polke BG, Raha KC. Characterization of $\gamma$ - and $\alpha-\mathrm{Fe}_{2} \mathrm{O}_{3}$ Nano powders synthesized by emulsion precipitationcalcination route and rheological behaviour of $\alpha-\mathrm{Fe}_{2} \mathrm{O}_{3}$. Int J Eng Sci Technol 2010;2:118-26. 